\title{
Programadores do Amanhã: Introdução ao Pensamento Computacional na Educação Básica
}

\author{
Givanaldo Rocha de Souza1, Stephanny Kawany M. Nunes1, Marília Barbosa C. do \\ Nascimento1, Estevão Henrique L. Ferreira1
}

1Instituto Federal de Educação, Ciência e Tecnologia do Rio Grande do Norte (IFRN), Campus Parnamirim - Brasil

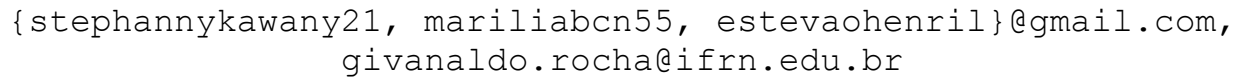

\begin{abstract}
This article describes the experience of an introduction course about computational thinking in basic education through block programming using Scratch. We analyzed the experiences of Programmers of Tomorrow project, which consists in taking to students of public schools the knowledge in Computer Programming, carried out by students of the technical course integrated in Informatics and of the superior course of Systems Technology for the Internet, both from the Federal Institute of Education, Science and Technology (IFRN), Parnamirim Campus.
\end{abstract}

Resumo. Este artigo tem como objetivo descrever o relato de experiência de um curso de introdução ao pensamento computacional na educação básica por meio da programação em blocos usando o Scratch. Para isso, foram analisadas as experiências vividas no projeto Programadores do Amanhã, o qual consiste em levar para alunos de escolas públicas o conhecimento em Programação de Computadores, realizado por alunos do curso técnico integrado em Informática $e$ do curso superior de Tecnologia em Sistemas para Internet, ambos do Instituto Federal de Educação, Ciência e Tecnologia (IFRN), Campus Parnamirim.

\section{Introdução}

O projeto Programadores do Amanhã tem como objetivo disseminar o pensamento computacional por meio da programação em blocos utilizando o Scratch, despertando o interesse pela área de computação e motivando os alunos a ingressarem em um curso na área. "Todos neste país deveriam aprender a programar um computador, pois isto ensina a pensar”. Essa frase de Steve Jobs já explica a motivação para o projeto e pode ser trazida para o contexto nacional. $O$ ensino de programação, além de ajudar a pensar e desenvolver o raciocínio lógico, faz com que os alunos tenham uma capacidade ainda maior para resolver problemas que são encontrados não apenas nos códigos, é uma porta de entrada para um mundo com novas possibilidades.

A computação pode ser definida como a busca de uma solução para um problema a partir de entradas de dados e por meio de um algoritmo. É um subcampo da ciência da computação matemática e que durante centenas de anos foi executada com caneta e papel, giz, ardósia, ou somente mentalmente, por vezes com o auxílio de tabelas, ou utensílios 
artesanais. Segundo Amaral et al. (2014, p. 1475), a computação pode ser entendida como "a ciência que estuda [...] Algoritmos, Complexidade Computacional, Organização de Computadores, Linguagens de Programação, Redes de Computadores, Banco de Dados, Sistemas Operacionais, entre outros. [...]".

O crescimento tecnológico permitiu uma mudança de paradigmas no ensino, pois surgiu a necessidade de lidar e interagir com os conceitos do raciocínio lógico aplicado a ambientes digitais. No transcurso das quatro últimas décadas, houve um grande avanço na utilização do computador e, com isso, possibilitou uma evolução significativa nas interfaces homem-máquina, promovendo uma ação de conquista em dispositivos eletrônicos e expandindo pelo baixo custo de matérias e equipamentos que possibilitam o aprendizado por meio de uma lógica de programação e a experiência de ferramentas e cenários como recursos didáticos [Mélo et al. 2011]. Esta contribuição possibilita substancialmente o aprendizado da lógica de programação por meio de ferramentas, cenários operacionais que buscam praticar e instigar a construção constante e continuada do conhecimento, com base na experimentação própria das necessidades do aluno [Papert, apud Mélo et al. 2011].

O advento tecnológico fez surgir um novo profissional na área da educação como forma de mediar a tecnologia ao processo metodológico de ensino-aprendizagem, por meio da "Disseminação do Pensamento Computacional". Busca-se utilizar uma revisão da literatura que contemple as possibilidades de desenvolvimento do pensamento computacional, dentre eles, destacam-se Amaral et al. (2015), França e Amaral (2015), Mélo et al. (2015) e Rocha (2013). Consequentemente, quando nos voltamos para a inserção da Informática na Educação precisamos ressaltar que tal consideração busca uma fundamentação significativa para sua consolidação no currículo escolar e com isto podemos encontrar algumas discussões por parte dos educadores sobre este assunto. Portanto, uma das formas de inserção da computação nas escolas é por meio de projetos de tecnologia aplicados em sala de aula e por imediato acaba sendo um modo de mostrar e cultivar a motivação dos educandos pela área de tecnologia quando forem cursar uma universidade.

O Scratch é um software que utiliza uma linguagem muito semelhante aos blocos construtivos de brinquedos Lego, estimulando a criatividade. Assim, precisamos ponderar que para "uma filosofia particular inspirado nos brinquedos da Lego e por uma pedagogia socioconstrutivista" [Rocha 2013], podemos propor que o usuário possa criar os mais diversos projetos. Estes conceitos procuram diminuir a problemática do processo de ensino-aprendizagem, adicionando o interesse e a motivação dos educandos transversalmente por meio dos jogos, que acabam exercendo influência sobre os educandos [Rocha 2013]. Assim, como ferramenta para se aplicar os conceitos de lógica de programação, utilizamos o Scratch para introduzir estes educandos a pensar computacionalmente.

Por meio deste projeto, priorizamos fazer com que os alunos desenvolvessem a capacidade de pensar e resolver problemas. Hadi Partovi, criador da iniciativa Code.org, acredita que a programação é uma incrível e poderosa habilidade para se aprender. Tivemos por objetivo com esse projeto fazer com que mais pessoas se envolvessem com a programação e motivar cada vez mais crianças e adolescentes a entrar no mundo da computação. Podemos considerar que esta metodologia se tornou significativa, quando nos voltamos ao desenvolvimento de jogos, que vem a ser de grande aceitação pelas crianças e jovens. 
Este artigo é composto por mais três seções. A segunda seção descreve a motivação para o projeto e como o mesmo foi planejamento para ser executado na escola. A terceira seção apresenta os jogos que foram desenvolvidos durante o projeto. Finalmente, a quarta seção apresenta as considerações finais e perspectivas futuras a respeito da execução do projeto.

\section{Motivação e planejamento do projeto}

Desde que o conceito do pensamento computacional foi popularizado por Wing (2006), um grande número de iniciativas de ensino de programação e robótica tem surgido para que crianças e jovens possam ter habilidades nessas áreas e estimular o raciocínio lógico. Blikstein (2008) relata que aprender a programar é uma das etapas mais importantes para o desenvolvimento do pensamento computacional, independente de usar uma linguagem de programação (C, Java, Python, Ruby etc.). Assim, o ensino de programação utilizando uma linguagem de blocos, como o Scratch, possibilita a crianças e jovens aprenderem a programar de forma lúdica, sem as amarras e sintaxes de uma linguagem de programação, preocupados em desenvolver o raciocínio lógico.

Existem diversas iniciativas no ensino de programação com Scratch, tais como minicursos e oficinas [Silva, Souza e Morais 2016, Madeira 2017, Marinho 2017]. Essas iniciativas, em sua maioria, usam metodologias de aprendizagem baseadas em criação de jogos digitais [Silva e Falcão 2017], uma vez que os jogos são atrativos na faixa etária da educação básica, além de estimular o lúdico, explorando a criatividade dos alunos.

O projeto Programadores do Amanhã foi planejado baseado nas ideias descritas no parágrafo anterior, fazendo uso de oficinas e de um projeto de criação de jogos digitais. Ele foi executado na Escola Municipal Augusto Severo, na cidade de Parnamirim-RN, com alunos do $8^{\circ}$ e $9^{\circ}$ anos do ensino fundamental. A equipe foi composta por um professor de sistemas de informação, que coordenou o projeto, e três alunos do curso técnico de Informática, todos do IFRN - Campus Parnamirim, e teve duração de um ano.

O projeto foi planejado em duas etapas: Informática básica e Programação. Essa divisão foi necessária, pois não se sabia o nível de conhecimento dos participantes e, como são dois assuntos que estão muito interligados, foi abordado, mesmo que de uma maneira rápida, o conteúdo de informática básica antes de inserir a programação nas aulas.

\subsection{Informática básica}

Os recursos atuais da tecnologia e os novos meios digitais (a multimídia, a Internet e a telemática) trazem novas formas de ler, de escrever, e, portanto, de pensar e agir. $\mathrm{O}$ simples uso de um editor de texto mostra como alguém pode registrar seu pensamento de forma distinta daquela do texto manuscrito ou mesmo datilografado, provocando no indivíduo uma forma diferente de ler e interpretar o que escreve, forma esta que se associa ora como causa, ora como consequência, a um pensar diferente [Fróes 1994, p. 18]. A informática é importante para sociedade moderna, pois a todo momento precisamos utilizá-la, seja de forma direta ou indireta. Sendo assim, é essencial que todo ser humano tenha os conhecimentos básicos da informática. Com esse pensamento, desenvolvemos com os alunos aulas relacionadas a esse assunto, fornecendo a base da informática. Foram ministradas aulas de introdução aos sistemas operacionais, editor de texto, planilha eletrônica e Internet. 
Com base em um questionário aplicado no final do projeto podemos notar que todos os participantes acharam relevante aprender informática básica para o evoluir do projeto e para a utilização em outras questões práticas do cotidiano.

\subsection{Programação}

Os alunos que participaram do projeto estavam cursando o $8^{\circ}$ e o $9^{\circ}$ anos do ensino fundamental e, até o iniciar as aulas, nunca tinham tido contato com a programação. Portanto, foi necessário garantir que o primeiro contato desses alunos com a área da computação gerasse compreensão e motivação para os envolvidos. Sendo assim, foi abordado um tipo de programação mais simples e mais dinâmica, sendo por esse motivo o Scratch a plataforma escolhida para trabalhar durante o projeto.

O Scratch foi desenvolvido pelo MediaLab do MIT, para que o usuário pudesse programar histórias interativas, jogos e animações, com a possibilidade de compartilhar suas criações com outros membros da comunidade online. Além de ser voltada especialmente para estudantes entre 8 e 16 anos [Scratch 2015].

Quando perguntado aos alunos no questionário final se eles haviam tido alguma dificuldade dentro da área de programação, foi visto que o nível de dificuldade deles ficou entre pouco e médio, ou seja, embora eles tenham sentido dificuldade na área da programação, ela não comprometeu a compreensão e desenvolvimento das aulas. $\mathrm{Na}$ figura 1 é mostrado em termos numéricos o resultado da enquete em questão.

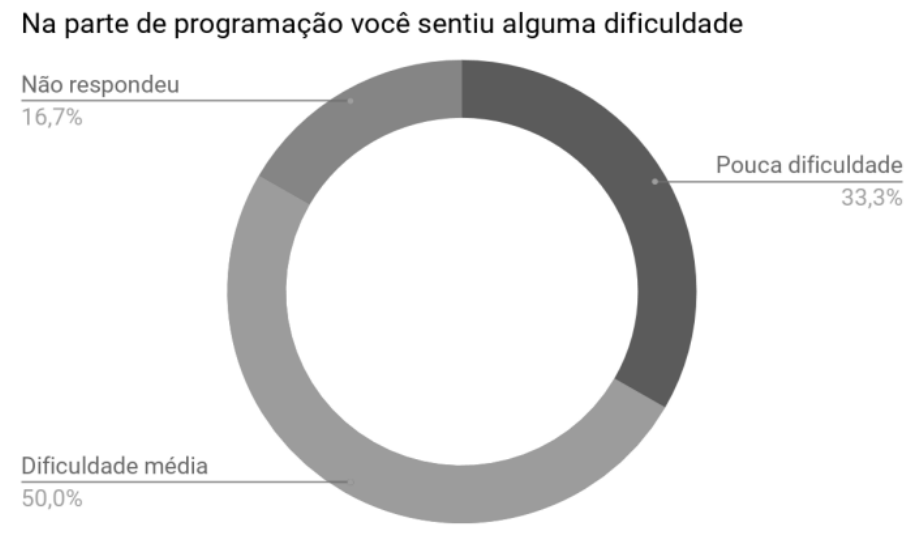

Figura 1. Dificuldade dos alunos na área de programação ao final do curso

Durante o decorrer aulas, foi observado uma maior motivação e participação dos alunos nas aulas práticas de desenvolvimento dos jogos utilizando o Scratch. Esse fato foi importante para expandir o interesse dos alunos pela informática, gerando melhor relação entre os estudantes e a plataforma de programação, pois foi nítido a busca pela compreensão do software, mediante a quantidade de dúvidas e curiosidades apresentadas ao decorrer das lições. Na figura 2, é possível comprovar essa preferência por meio do questionário final, o qual todos os alunos que expressaram sua opinião demonstraram maior interesse pela parte da programação. 


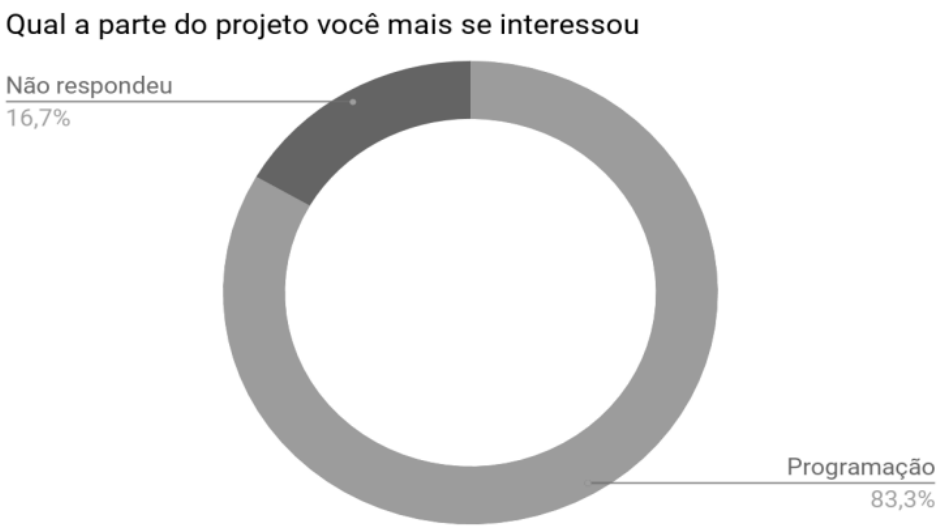

Figura 2. Parte de maior interesse: Informática básica ou programação

\section{Jogos desenvolvidos no projeto}

Os jogos de computador desempenham um papel muito importante na vida dos nossos jovens [Murray 1999, Turkle 1997, Overmars 2004, Maloney et al. 2008, Resnick et al. 2009, Paraskeva et al. 2010]. Por ser algo do cotidiano dos alunos, optou-se pelo desenvolvimento de jogos digitais como projeto final, com o intuito de os alunos desenvolverem seus próprios jogos, uma vez que o Scratch permite criar facilmente jogos com potencial educativo [Marques 2013].

$\mathrm{Na}$ fase final do projeto, os encontros foram reservados para que os alunos desenvolvessem o jogo digital no Scratch. Os jogos foram desenvolvidos em grupos para que, além de aprender a trabalhar em grupo, eles também pudessem se ajudar à medida em que fossem surgindo dúvidas ou dificuldades. Essa abordagem em grupo foi muito eficiente, uma vez que foi perceptível que os alunos procuravam encontrar respostas para os problemas que iam aparecendo de acordo com o desenvolvimento do jogo entre eles mesmos antes de procurarem os instrutores. Foram criados três grupos e desenvolvidos três jogos distintos ao final do projeto.

O grupo 1 desenvolveu um jogo baseado na tabuada (Figura 3). O personagem cita uma multiplicação e a cada resposta certa ele adiciona pontos para o placar do jogador, mas caso o jogador erre o resultado, aparece uma mensagem dizendo que a resposta está errada e em seguida aparece outra multiplicação. O grupo que desenvolveu o jogo já determinou o tempo que cada partida deve durar. 


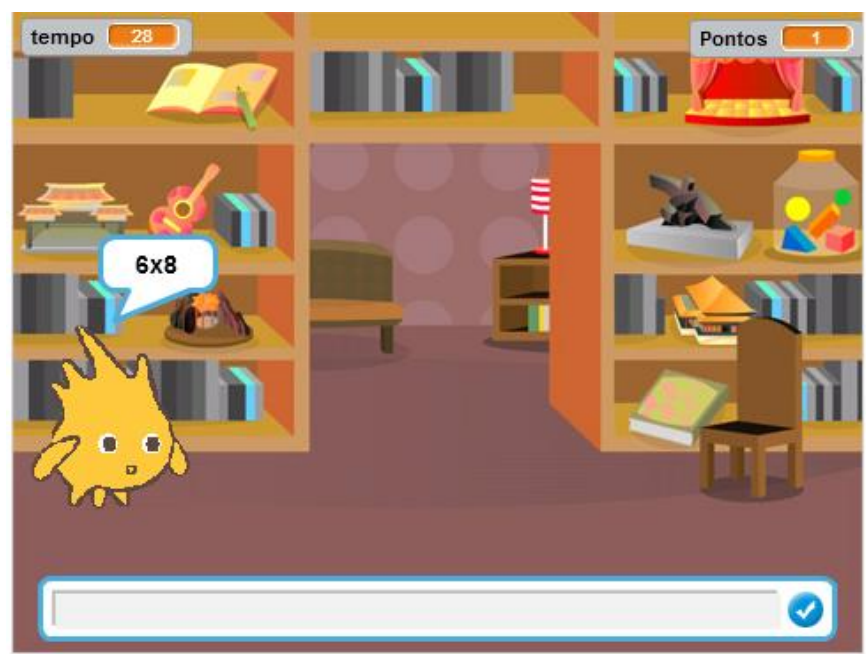

Figura 3. Jogo desenvolvido pelo grupo 1

O grupo 2 desenvolveu um jogo que consiste em utilizar a barra verde para controlar a passagem da bola laranja a qual está em movimento constante (Figura 4), algo parecido com o jogo Pong. Durante o jogo, na parte superior esquerda conta a pontuação durante o jogo e a parte superior direita informa o recorde da pontuação. Caso a bola atinja a barra vermelha o jogo paralisa, exibe uma mensagem que o jogador perdeu e reinicia quando é clicado qualquer botão do teclado.

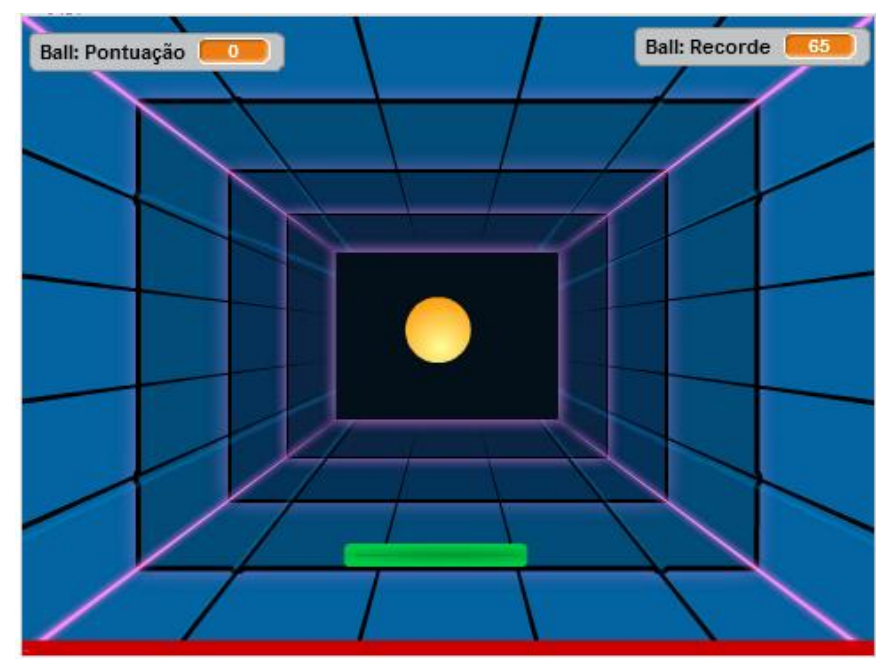

Figura 4. Jogo desenvolvido pelo grupo 2

O grupo 3 desenvolveu um jogo baseado no Fruit Ninja (Figura 5), onde aparecem frutas constantemente e é necessário clicar nelas para que essas sumam, aumentando a pontuação da partida. Para isso, cada fruta soma uma quantidade de pontos diferente, aparecem na tela e percorrem o sentido vertical em um tempo aleatório. 


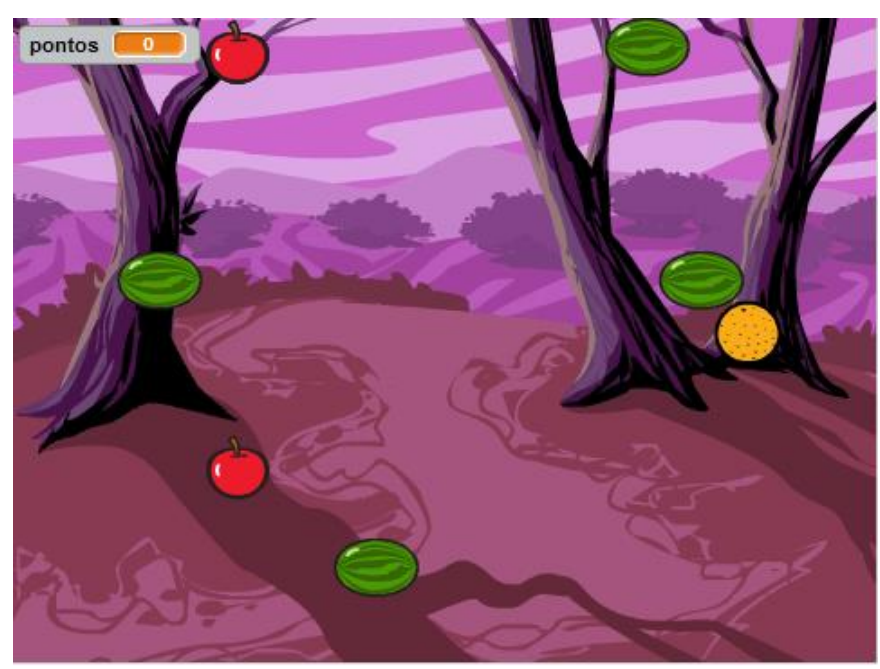

Figura 5. Jogo desenvolvido pelo grupo 3

É possível perceber que em uma mesma plataforma os alunos desenvolveram jogos com objetivos diferentes, ou seja, eles tiveram percepções diferentes do mesmo assunto. Isso ocorre pelo fato do Scratch, apesar de ser uma programação em blocos, oferece diversas possibilidades de criação e diferentes formas para o desenvolvimento delas.

A apresentação do trabalho final ocorreu na aula de encerramento do projeto. Um convite foi enviado aos gestores da escola para que pudessem prestigiar a apresentação dos jogos desenvolvidos pelos seus alunos (Figura 6).

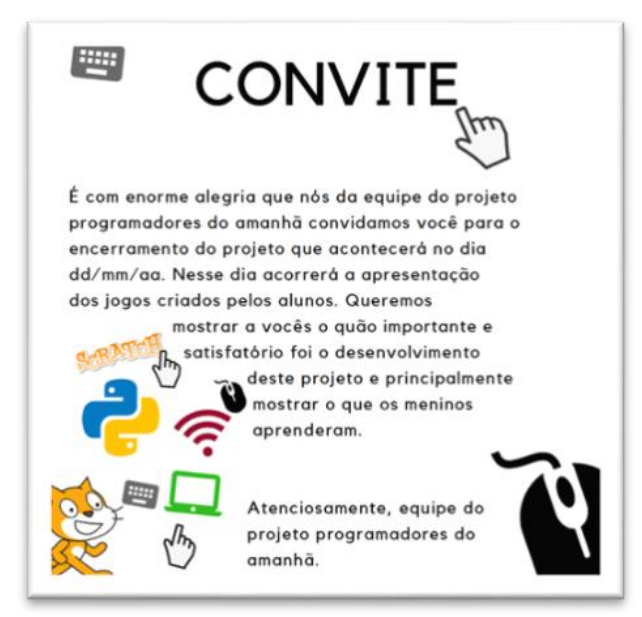

Figura 6. Modelo do convite enviado aos gestores da escola

No laboratório onde ocorreram as aulas, os grupos projetaram os jogos no espaço disponível e apresentaram como tiveram as ideias para o jogo, o método utilizado para concretizar essas ideias, as dificuldades enfrentadas e como funcionava o jogo, finalizando com a demonstração prática. Ao final das apresentações, todos os alunos concluintes receberam certificado de participação no projeto.

Houveram algumas dificuldades no desenvolvimento dos jogos, pois, embora tenham praticado no decorrer do projeto com exercícios, na hora de desenvolver algo que não tinha um roteiro foi mais complicado. Foi possível perceber que surgiram muitas dúvidas, perguntas do tipo “qual bloco usar?”, “o que vem a seguir?", “qual jogo fazer?” 
foram bem comuns. Por vezes, os blocos não faziam o que os alunos esperavam, mas com calma, tempo e ajuda foi possível ver o crescimento do conhecimento dos alunos.

No que diz respeito às dúvidas que surgiram, os alunos foram encorajados a seguirem três passos: $1^{\circ}$ ) tentar encontrar o erro, $2^{\circ}$ ) pedir ajuda ao(s) colega(s) e $3^{\circ}$ ) se tudo falhasse, procurariam os instrutores. Isso foi encorajado porque essa discussão colaborativa é muito importante, faz com que os alunos se esforcem mais, pensem, repensem, desenvolvendo o raciocínio lógico deles. Vale ressaltar que objetivo principal do desenvolvimento dos jogos não era medir o conhecimento dos alunos, mas sim incentivar os mesmos a procurarem aprender mais, a tentarem com erros e acertos, além de procurarem uma aprendizagem colaborativa com a turma.

\section{Considerações finais}

Nos primeiros momentos, o projeto enfrentou dificuldades para a execução do planejamento, como a infraestrutura e ausência de conhecimento dos alunos sobre informática e programação. Porém, a contribuição entre os professores e os alunos possibilitou o andamento do mesmo. Diante dessa colaboração, ao final das aulas, os resultados dos questionários avaliativos mostram o resultado satisfatório do projeto.

A partir dos objetivos alcançados, a experiência do projeto demonstra a possibilidade de trazer a programação ao cotidiano de crianças e adolescentes, os quais nunca tiveram a chance do acesso a essa prática. Além disso, comprova-se também a importância do propósito de introduzir a programação na educação básica para melhorar o desempenho do raciocínio lógico na resolução de problemas práticos ou técnicos.

Como projeto futuro, o grupo pretende incluir atividades de computação desplugada nas escolas em que a estrutura de laboratório seja insuficiente ou precária para se usar o Scratch em um laboratório de informática.

\section{Referências}

Amaral, H. J. C. et al (2014). A disseminação do pensamento computacional na educação básica: lições aprendidas com experiências de licenciandos em computação. Anais do XXXIV Congresso da Sociedade Brasileira de Computação (CSBC).

Blikstein, P. (2008). O Pensamento Computacional e a Reinvenção do Computador na Educação. Disponível em: <http://bit.ly/11XlbNn>.

França, R. S.; Amaral, H. J. C. (2013). Proposta Metodológica de Ensino e Avaliação para o Desenvolvimento do Pensamento Computacional com o Uso do Scratch. Anais do II Congresso Brasileiro de Informática na Educação (CBIE).

Fróes, J. A. (1994). Tecnologia na vida cotidiana: - importância e evolução sóciohistórica. Rio de Janeiro.

Madeira, Charles (2017). Introdução ao Pensamento Computacional com Scratch. In: Anais do II Congresso sobre Tecnologias na Educação (CTRL+E-2017). p. 725-730.

Marinho, Anna R. da Silva et al (2017). O uso do Scratch na Educação Básica: Um relato de experiência vivenciada no PIBID. In: Anais do Workshop de Informática na Escola. p. 402.

Marques, M. C. P. O. (2013). O ensino da programação no desenvolvimento de jogos através do ambiente Scratch. Tese do mestrado em Ensino de Informática da Universidade do Minho, Braga. 
Mélo, F. É. N. et al. Do Scratch ao Arduino: uma proposta para o ensino introdutório de programação para cursos superiores de tecnologia. Anais do XXXIX Congresso Brasileiro de Educação em Engenharia (COMBEGE), 2011.

Rocha, A. S. et al. Utilização do Scratch como ferramenta de auxílio à aprendizagem de programação. Anais do XLI Congresso Brasileiro de Educação em Engenharia (COMBEGE), 2013.

Scratch. (2015) “About Scratch”, http://scratch.mit.edu/about.

Silva, João Paulo da; Falcão, Taciana Pontual. Jogos Infantis e Pensamento Computacional: em Busca de um Conjunto de Diretrizes de Design. 2017.

Silva, Vladimir; Souza, Aryesha; Morais, Dyego. Pensamento Computacional no Ensino de Computação em Escolas: Um Relato de Experiência de Estágio em Licenciatura em Computação em Escolas Públicas. In: Congresso Regional Sobre Tecnologias na Educação. 2016. p. 324-325.

Wing, J. (2006). Computational Thinking. Communications of the ACM, 49(3): 33-36. 